\title{
Sistem aliran dan potensi airtanah di sebagian Desa Sembangun ditinjau dari aspek kuantitas dan kualitas
}

\author{
Melati Ayuning Putri, Anindya Arma Risanti, Kurniawan Andre Cahyono, Latifah Latifah, Novita Rahmawati, \\ Roesdi Fitra Ariefin, Safira Prameswari, Wisnu Agung Waskita, Tjahyo Nugroho Adji, dan Ahmad Cahyadi
}

Geografi Lingkungan, Fakultas Geografi, Universitas Gadjah Mada, Indonesia

Email Koresponden: melatipuput21@gmail.com, ahmadcahyadi@geo.ugm.ac.id

Diterima: Januari 2018/Refisi: Februari 2018 Disetujui: September 2018

(c) 2018 Fakultas Geografi UGM dan Ikatan Geograf Indonesia (IGI)

\begin{abstract}
Abstrak Desa Sembungan merupakan daerah recharge area dengan resapan air yang disuplai oleh banyak bukit di sekitarnya sehingga pola ruang airtanahnya difungsikan untuk arahan konservasi. Berdasarkan hal tersebut peneliti tertarik untuk mengkaji potensi airtanah Desa Sembungan beserta sistem alirannya, mengingat airtanahnya yang juga dimanfaatkan oleh penduduk untuk berbagai keperluan, seperti domestik, pertanian, dan wisata. Tujuan dari penelitian ini yaitu (1) mengidentifikasi sistem aliran airtanah, (2) mengestimasi kuantitas airtanah, dan (3) menganalisis kondisi kualitas airtanah di Desa Sembungan. Penelitian menggunakan pendekatan kuantitatif dan kualitatif dengan mengumpulkan data primer melalui metode sensus sumur dan mataair di Desa Sembungan. Lokasi sumur untuk pumping test metode slug test ditentukan dengan teknik purposive sampling. Hasil penelitian menunjukkan kondisi airtanah yang melimpah dan mengalir dari arah utara menuju barat daya yang merupakan lembah dengan mataair. Desa Sembungan memiliki nilai konduktivitas hidrolik sebesar $0.0196 \mathrm{~m} /$ hari, potensi airtanah dengan debit dinamis sebesar 726,24 liter/hari dan debit rata-rata mataair sebesar 1,15 liter/detik. Potensi lainnya berupa kualitas air sumur di permukiman dan mataair termasuk kategori aman untuk memenuhi kebutuhan domestik apabila dilihat dari parameter suhu, DHL, TDS, dan $\mathrm{pH}$, karena hampir seluruhnya menunjukkan nilai sesuai dengan baku mutu yang ditetapkan.
\end{abstract}

Kata kunci: potensi airtanah, flownet, kualitas dan kuantitas airtanah

\begin{abstract}
Sembungan Village is a recharge area that supplied by many hills around, so its pattern of groundwater reservoir should be functioned for conservation. Based on the fact that researchers interested in conducting research on groundwater potency and its flow system in Sembungan Village because the groundwater also used for many needs, such as domestic, agriculture, and tourism. The purposes of this research are 1) to identify the groundwater flow system, 2) to estimate the quantity of groundwater, and 3) to analyze the groundwater quality in Desa Sembungan. The study used quantitative and qualitative approach by censused all wells and springs to collect the primary data. Purposive sampling used to determine the location of pumping test with slug test method. The results showed that abundant supply of groundwater flows from north to southwest, leading to a valley and springs. The hydraulic conductivity value in Desa Sembungan is $0.0196 \mathrm{~m} /$ day. Its potential groundwater as illustrated through debit from dynamic method is 726.24 liters/day and the average debit of five springs in the valley is 1.15 liters/s. Water quality in settlements and springs still quite safe for villager's need, including domestic use. Almost all the value of temperature, conductivity, total dissolved solid, and $\mathrm{pH}$ were not meet quality standards that have been determined.
\end{abstract}

Keywords: groundwater potency, flownet, groundwater quantity and quality

\section{PENDAHULUAN}

Airtanah merupakan air yang menempati pori-pori batuan di bawah permukaan tanah pada zona jenuh air (Santosa dan Adji, 2014). Sumberdaya airtanah bersifat dapat diperbaharui secara alami karena airtanah merupakan bagian yang tidak terpisahkan dalam siklus hidrologi (Asrifah, 2012). Keberadaan airtanah dapat dijumpai di hampir seluruh tempat di Bumi, bahkan di bawah lapisan es yang membeku airtanah dapat ditemukan (Asdak, 1995).

Keterdapatan airtanah bergantung pada ada tidaknya lapisan batuan yang dapat menyimpan airtanah. Airtanah berada dalam formasi geologi yang disebut sebagai akuifer. Akuifer merupakan formasi yang dapat menyimpan dan mengalirkan air dalam jumlah yang cukup, yang artinya mampu mengaliri suatu sumur, sungai dan mataair (Sudarmadji dkk., 2016). Besarnya airtanah yang dapat disimpan dalam akuifer bergantung dari sifat-sifat akuifer tersebut serta luas cakupan dan frekuensi imbuhan (Linsley dan Franzini, 1985).

Daerah penelitian berada di Desa Sembungan, Kecamatan Kejajar, Kabupaten Wonosobo. Desa Sembungan merupakan salah satu desa yang terletak di Pegunungan Dieng bagian paling timur dengan luas 291.730 hektar. Desa Sembungan merupakan desa tertinggi di Pulau Jawa yang berada pada elevasi \pm 2350 mdpl. Kondisi geologi wilayah kajian secara umum merupakan satu kesatuan dari kawasan Gunungapi Dieng. Secara detail geologi, Desa Sembungan terletak pada garis sesar geser dengan arah relatif barat laut-tenggara yang dihasilkan dari kompresi lateral 
dari pergerakan Samudra Indonesia ke arah utara membentuk Lempeng Benua Asia. Desa Sembungan terdiri atas unit kerucut vulkanik G.Seroja, G.Sikunang, G.Pakuwaja, G.Prambanan, dan G.Sikunir yang mengelilingi.

Berdasarkan fakta tersebut, Desa Sembungan merupakan daerah recharge area yang memiliki resapan air yang besar karena disuplai oleh banyak bukit di sekitarnya, sehingga pola ruang airtanah tersebut difungsikan untuk arahan konservasi. Pola ruang airtanah merupakan distribusi peruntukan airtanah dalam suatu wilayah. Airtanah memiliki pola ruang dalam satuan catchment area berupa Cekungan Air Tanah (CAT) (Kodoatie, 2010). Salah satu kriteria CAT adalah memiliki satu kesatuan sistem akuifer yang di dalamnya terdiri atas akuifer bebas dan akuifer tertekan. Namun demikian, penelitian ini hanya difokuskan pada akuifer bebas Desa Sembungan yang merupakan bagian dari CAT Wonosobo. Adapun tujuan dari penelitian ini yaitu (1) mengidentifikasi sistem aliran airtanah di Desa Sembungan, (2) mengestimasi kuantitas airtanah di Desa Sembungan, dan (3) menganalisis kualitas airtanah di Desa Sembungan. Informasi terkait kondisi sumberdaya air di wilayah kajian baik dari segi kuantitas maupun kualitas diperlukan untuk pengelolaan sumberdaya air yang lebih berkelanjutan, mengingat bahwa Desa Sembungan memiliki potensi pertanian dan pariwisata yang sedang berkembang yang berpotensi menambah kebutuhan air di masa mendatang.

\section{METODE PENELITIAN}

Penelitian ini menggunakan pendekatan kuantitatif dan kualitatif. Kuantitas airtanah berupa debit dinamis airtanah dan mataair diukur secara kuantitatif, sedangkan kualitas airtanah dan arah aliran airtanah diidentifikasi secara kualitatif. Survei lapangan dengan sensus sumur dan mataair di Desa Sembungan digunakan untuk memperoleh data kedalaman airtanah, kualitas air baik sumur maupun mataair, dan debit mataair. Selain itu, dilakukan pengukuran beda tinggi dengan membuat transek/profiling guna memperoleh elevasi sumur. Lokasi untuk pumping test metode Shalow Dug Well Recovery Test (Slug Test) ditentukan menggunakan purposive sampling dengan pertimbangan keadaan sumur yang memiliki dinding lolos air dan tidak menembus lapisan impermeabel yang menjadi salah satu syarat dari slug test. Alat yang digunakan dalam penelitian ini, yaitu Global Positioning System (GPS), meteran, water checker, aquades, ember, yallon, kompas geologi, distrometer, stopwatch, seperangkat alat pumping test, dan Automatic Water Level Recorder (AWRL).

Pola aliran airtanah (flownets) daerah kajian diperoleh dengan pengukuran kedalaman muka airtanah dan elevasi sumur yang diolah menjadi tinggi muka airtanah (TMA) di 25 sumur. Interpolasi linear TMA dengan metode three point problem digunakan untuk membuat kontur airtanah secara manual dan digital. Kemudian arah aliran airtanah ditentukan dengan menarik garis tegak lurus terhadap garis kontur airtanah.

Estimasi potensi airtanah ditunjukkan oleh debit airtanah yang merupakan pergerakan airtanah persatuan waktu. Perhitungan debit airtanah dilakukan dengan bantuan peta flownet dan pendekatan Darcy yang ditunjukkan pada persamaan 1 (Todd, 1980). Nilai K dihitung dari hasil pengukuran menggunakan metode slug test pada persamaan 2 dan 3. Metode tersebut dipilih karena tidak seluruh dinding sumur kedap air dan sumur tidak menembus penuh akuifer (Gambar 1).

$$
\mathbf{Q}=\mathbf{K} \times \mathbf{A} \times \mathbf{I}
$$

\section{Keterangan:}

Q : total debit per unit lebar akuifer $\left(\mathrm{m}^{3} /\right.$ hari)

$\mathrm{K}$ : hydraulic conductivity ( $\mathrm{m} / \mathrm{hari})$

A : luas penampang akuifer $\left(\mathrm{m}^{2}\right)$

I : gradien hidrolik

$$
\begin{aligned}
K & =\frac{r c^{2} \ln (R e / r w)}{2 d} \cdot \frac{1}{t} \cdot \ln \frac{S o}{S t} \ldots \\
\operatorname{Ln} R e / r w & =\left[\frac{1,1}{\ln (b / r w)}+\frac{A+B \ln [(D-b) / r w]}{d / r w}\right]^{-1}
\end{aligned}
$$

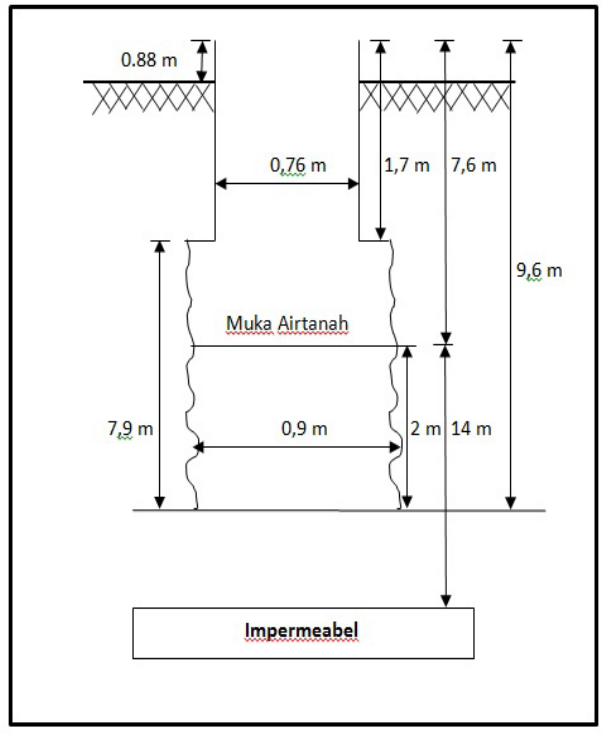

Gambar 1. Dimensi sumur pumping test hasil pengukuran

Perhitungan debit mataair menggunakan rumus volumetric method pada persamaan 4 yang kemudian dicocokkan dengan Tabel 1.

$$
\mathbf{Q}=\mathbf{A} \times \mathbf{V}
$$


Keterangan:

Q : debit aliran $\left(\mathrm{m}^{3} /\right.$ detik)

A : luas penampang saluran $\left(\mathrm{m}^{2}\right)$

$\mathrm{V} \quad$ : Kecepatan aliran air $(\mathrm{m} /$ detik$)$

Tabel 1. Klasifikasi Debit Mataair

\begin{tabular}{cc}
\hline Kelas & Debit (liter/detik) \\
I & $\geq 10.000$ \\
II & $1000 \leq \mathrm{x} \leq 10.000$ \\
III & $100 \leq \mathrm{x} \leq 1000$ \\
IV & $10 \leq \mathrm{x} \leq 100$ \\
V & $1 \leq \mathrm{x} \leq 10$ \\
VI & $0.1 \leq \mathrm{x} \leq 1$ \\
VII & $0.01 \leq \mathrm{x} \leq 0.1$ \\
VIII & $<0.01$ \\
\hline
\end{tabular}

Sumber: Todd (1980)

Kualitas airtanah diketahui dengan cara menganalisis beberapa parameter, seperti suhu, Daya Hantar Listrik (DHL), Total Dissolved Solid (TDS), dan derajat keasaman atau $\mathrm{pH}$ di lapangan. Besarnya nilai parameter tersebut kemudian dibandingkan dengan Peraturan Pemerintah Nomor 82 Tahun 2001 tentang Pengelolaan Kualitas Air dan Pengendalian Pencemaran Air Kelas I, yakni baku mutu untuk air minum.

\section{HASIL DAN PEMBAHASAN}

Analisis pergerakan aliran airtanah di Desa Sembungan dibatasi oleh sistem airtanah di area permukiman. Pembatasan sistem airtanah di Desa Sembungan ini berupa tebing lembah dan Telaga Cebong. Kedua objek tersebut menjadi batas sistem aliran airtanah karena adanya kemunculan mataair dan permukaan telaga yang diasumsikan sebagai tinggi muka airtanah (TMA). Sistem aliran airtanah pada dasarnya mencakup daerah imbuhan dan daerah lepasan. Kemunculan mataair akibat adanya kontak airtanah dengan batuan impermeable merupakan salah satu penanda daerah lepasan. Mataair tersebut pada umumnya ditemukan di tekuk lereng pada ketinggian yang relatif sama (Kodoatie, 2010).

Pola aliran airtanah yang dihasilkan dari pembuatan peta flownet menunjukkan bahwa airtanah bergerak mengarah menuju ke barat daya, yakni daerah lepasan airtanah yang berupa mata air di dalam lembah. Peta flownet yang dibuat secara manual dan digital menunjukkan pola aliran yang relatif sama (Gambar 2) dilihat dari kontur airtanah dan pola arah aliran. Meskipun demikian, jika dibandingkan dengan metode konvensional, arah aliran airtanah dan kontur airtanah yang divisualisasikan secara digital menggunakan metode krigging geostatistical analysis dalam software ArcGIS relatif kurang baik. Terdapat banyak garis kontur airtanah yang mengelompok dan hasil memiliki RMS error yang besar (lebih dari 200) sehingga kurang merepresentasikan kontur kajian yang sebenarnya.

Pembuatan peta flownet secara manual dilakukan untuk menanggulangi kesalahan interpretasi akibat kerancuan arah aliran airtanah yang kurang beraturan. Aliran airtanah pada peta tersebut terlihat mengalir dari utara ke selatan dan barat daya, dengan TMA 2109 2076 mdpl. Aliran airtanah tidak seluruhnya mengarah menuju ke Telaga Cebong, melainkan hanya beberapa seperti dari timur laut daerah kajian yang memiliki TMA 2100 mdpl. Hal tersebut disebabkan oleh elevasi Telaga Cebong yang berkisar antara \pm 2.120 sehingga bukan merupakan daerah lepasan dan hanya menjadi pembatas sistem airtanah. Airtanah pada prinsipnya akan mengalir pada landaian hidrolika yang bergradasi semakin kecil. Morfologi muka airtanah menyerupai bentuk kerucut dan menyebar secara radial sesuai dengan penyebaran morfologi gunungapi (Hendrayana dkk., 2013).

Airtanah mengalir pada suatu penampang yang seragam dengan gaya gravitasi yang diperoleh dari kemiringan kontur airtanah (Hardjito, 2014). Nilai gradien hidrolik tiap segmen flownet yang berbeda dapat digunakan untuk mengetahui kemiringan airtanah secara absolut antara satu titik airtanah terhadap airtanah lainnya (Sudarmadji dkk., 2016). Airtanah mengalami pergerakan di dalam akuifer dengan kecepatan tertentu sehingga memiliki potensi airtanah yang bersifat dinamis.

Besarnya potensi airtanah berdasarkan pendekatan Darcy menghasilkan nilai konduktivitas hidrolik sebesar 0,0196 m/hari. Konduktivitas hidrolik merupakan besarnya nilai aliran airtanah yang melalui penampang $1 \mathrm{~m}^{2}$ di bawah pengaruh gradien hidrolik (Riyadi dkk., 2005). Nilai konduktivitas hidrolik bergantung pada jenis batuan yang menyusun akuifer. Berdasarkan klasifikasi Morris dan Johnson dalam Purnama (2010), nilai $\mathrm{K}$ tersebut setara dengan nilai $\mathrm{K}$ dari material basalt. Selain itu, hasil identifikasi lapangan juga ditemukan batuan beku ekstrusif berupa basalt. Batuan basalt merupakan batuan vulkanik yang membentuk akuifer dengan permeabilitas yang tinggi. Lava basalt biasanya berupa rekahan dengan banyak pori-pori bekas lubang gas dan mempunyai banyak retakan pada saat batuan tersebut membeku (Purnama, 2010). Oleh sebab itu, akuifer basalt mengandung air pada rekahan diantara bukaan gelembung gas pada lapisan atas atau bawahnya. Berdasarkan identifikasi material penyusun akuifer tersebut dapat diketahui bahwa nilai specific yield (Sy) wilayah kajian adalah sebesar 8\% (Heath, 1983).

Potensi airtanah dalam suatu cekungan sangat dipengaruhi oleh konfigurasi sistem akuifer batuan yang dikontrol oleh struktur geologi bawah permukaan (Hendrayana dkk., 2013). Perhitungan potensi airtanah dinamis dilakukan pada sepuluh penggal segmen kontur dan arah aliran airtanah secara merata, yaitu daerah utara (imbuhan), tengah (transisi), dan bawah yang dekat dengan mata air (lepasan). Hal tersebut dilakukan agar hasil debit yang diperoleh dapat merepesentasikan potensi daerah kajian yang sebenarnya. 

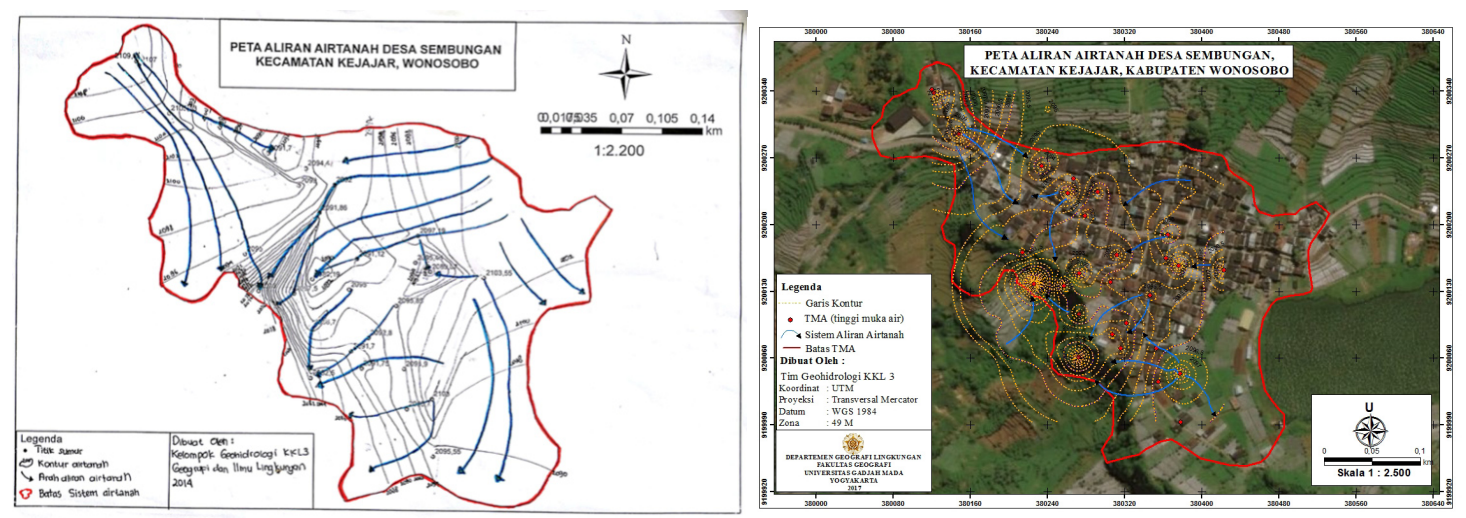

Gambar 2. Peta flownet airtanah yang dibuat secara manual (kiri) dan digital menggunakan software ArcGIS (kanan)

Tabel 2. Hasil perhitungan debit airtanah pada 10 segmen flownet

\begin{tabular}{cc}
\hline No & Q (liter/hari) \\
\hline 1 & 180.02 \\
2 & 176.42 \\
3 & 403.8 \\
4 & 1744 \\
5 & 304.3 \\
6 & 209.29 \\
7 & 627.5 \\
8 & 1506.9 \\
9 & 939.66 \\
10 & 174.61 \\
\hline
\end{tabular}

Rata-Rata: 726,24

Sumber: Olah data primer, 2017

Besarnya debit yang dihasilkan melalui perhitungan dipengaruhi oleh luas segmen flownet dan gradien hidrolik yang berbeda-beda. Rata-rata debit aliran airtanah pada sistem airtanah Sembungan adalah 726,24 liter/hari, yang nilainya cukup besar untuk dapat dimanfaatkan warga (Tabel 2). Sumberdaya airtanah yang dimanfaatkan di Desa Sembungan bukan hanya dari sumur gali milik warga, namun juga dari mataair. Penggunaannya sebagian besar untuk memenuhi kebutuhaan pariwisata berupa penginapan atau homestay dan sebagian lainnya untuk memenuhi kebutuhan domestik dan pertanian. Beberapa perkebunan yang berlokasi di bawah mataair tersebut diairi dengan memanfaatkan gaya gravitasi melalui pipa-pipa irigasi.

Terdapat lima mataair di lembah Desa Sembungan. Mataair 1 memiliki debit terbesar yaitu 2,13 liter/ detik (Tabel 3). Mataair 1 sering dimanfaatkan untuk keperluan mencuci pakaian, mandi hingga konsumsi masyarakat. Nilai debit terendah dimiliki oleh mataair 5 senilai 0,11 liter/detik karena hanya berupa rembesan. Rata-rata debit mataair Desa Sembungan adalah 1,15 liter/detik sehingga termasuk mataair kelas VI berdasarkan Meinzer (1923) dalam Purnama (2010) dengan debit rata-rata 0,1-1 liter/detik (Tabel 1). Seluruh mataair tersebut memiliki kontinuitas yang baik, yakni dapat diambil terus menerus dengan fluktuasi debit yang relatif tetap, baik pada saat musim kemarau maupun musim hujan.

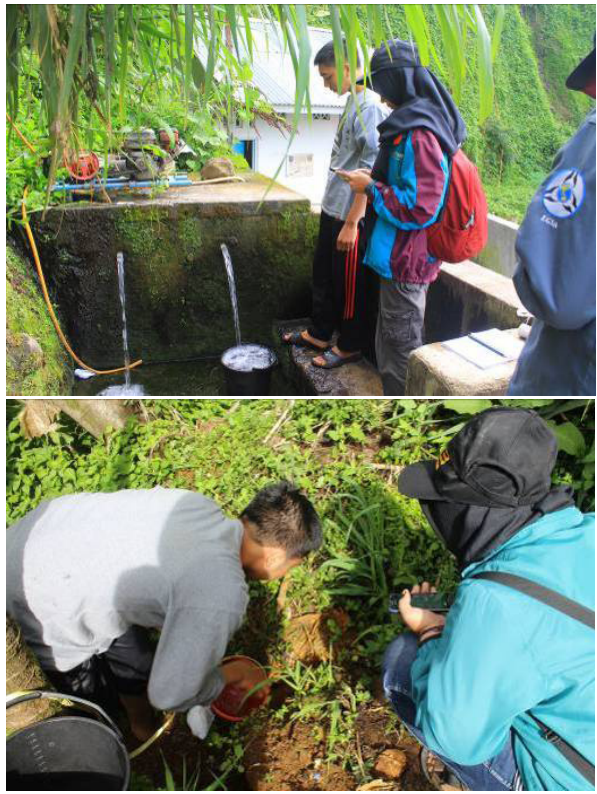

Gambar 3. Kondisi mataair 1 (atas) dan matair 5 (bawah) 
Peta flownet juga bermanfaat untuk menganalisis arahaliransifatkimiaairtanahataupunarahpencemaran. Kontak airtanah dengan batuan, serta kecepatan dan arah aliran airtanah sangat mempengaruhi kondisi hidrogeokimia airtanah. Aspek kualitas air merupakan komponen penting dalam keberlangsungan potensi dan fungsi ekologis air sehingga perlu perhatikan dengan baik. Hal tersebut ditegaskan dalam Peraturan Pemerintah Nomor 82 Tahun 2001 tentang Pengelolaan Kualitas Air dan Pengendalian Pencemaran Air.

Kondisi kualitas airtanah di wilayah kajian dapat dianalisis melalui pengukuran parameter kualitas, seperti berupa suhu, daya hantar listrik, Total Dissolved Solid (TDS), dan pH. Suhu airtanah di Desa Sembungan berada pada kisaran $<20^{\circ} \mathrm{C}$ (Gambar 6). Temperatur airtanah, khususnya pada mataair dan sumur gali sangat dipengaruhi temperatur udara (Sunarwan, dkk., 2015). Lokasi penelitian yang berada pada elevasi 2.075-2.104 mdpl menyebabkan suhu udara di daerah menjadi relatif rendah sehingga berdampak juga pada suhu airtanah yang menjadi rendah.

Hasil pengukuran di lapangan menunjukkan bahwa secara umum nilai DHL di Desa Sembungan memiliki variasi dengan kisaran $223 \mu$ mhos - 1.250 $\mu$ mhos dengan rata-rata $490.87 \mu$ mhos (Gambar 7). Berdasarkan Simoun (2000) airtanah wilayah kajian secara umum tergolong airtawar. Namun demikian, pada dua titik pengukuran ditemukan adanya airtanah yang tergolong payau.

Tabel 3. Hasil pengukuran debit mataair di Desa Sembungan

\begin{tabular}{ccccccc}
\hline $\begin{array}{c}\text { Mata- } \\
\text { air }\end{array}$ & $\begin{array}{c}\text { Waktu } \\
\text { pengukuran }\end{array}$ & X & $\begin{array}{c}\text { Koordinat } \\
\text { Y }\end{array}$ & Z & $\begin{array}{c}\text { Debit (l/ } \\
\text { detik) }\end{array}$ & Keterangan \\
\hline 1 & 7.35 & 380214 & 9200171 & 1972 & 2.13 & Dimanfaatkan masyarakat \\
2 & 7.59 & 380226 & 9200138 & 1976 & 1.29 & Dimanfaatkan pertanian \\
3 & 7.35 & 380297 & 9200462 & 1969 & 1.89 & Dimanfaatkan masyarakat \\
4 & 7.54 & 380257 & 9200136 & 1976 & 0.33 & Tidak dimanfaatkan (tercampur limbah) \\
5 & 8.25 & 380272 & 9200061 & 1990 & 0.11 & Dimanfaatkan pertanian \\
\hline
\end{tabular}

Sumber: Olah data primer, 2017

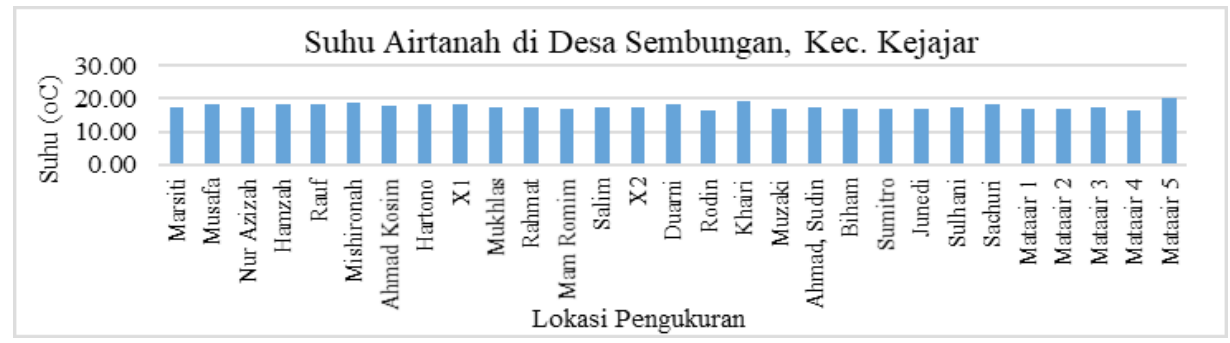

Gambar 6. Grafik nilai suhu airtanah Desa Sembungan

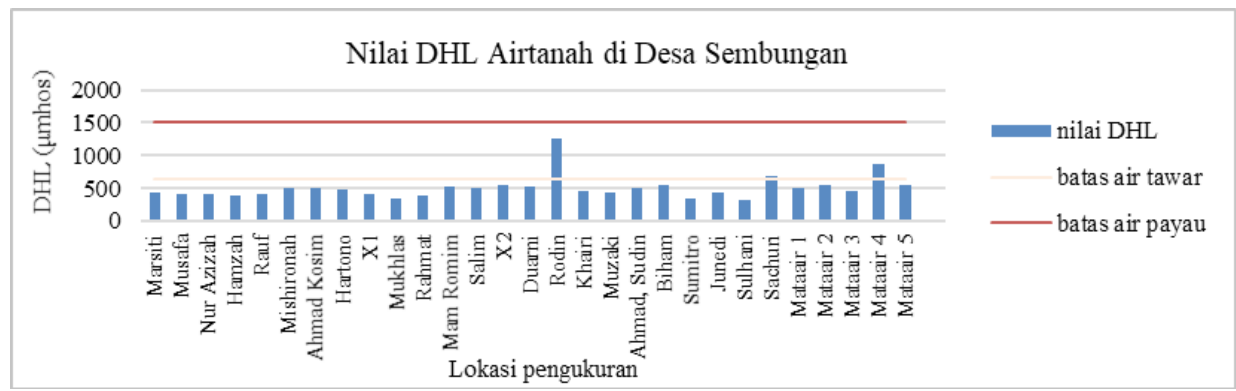

Gambar 7. Grafik nilai DHL airtanah Desa Sembungan

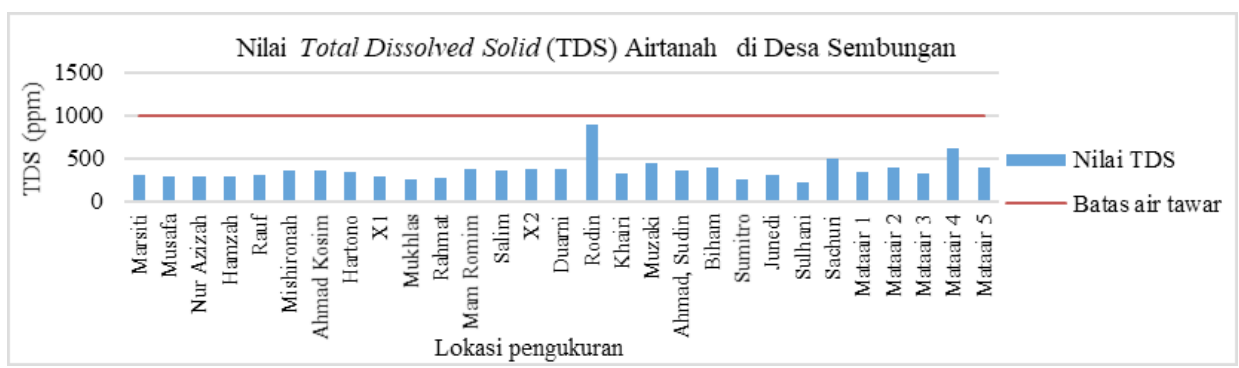

Gambar 8. Grafik nilai TDS airtanah Desa Sembungan 


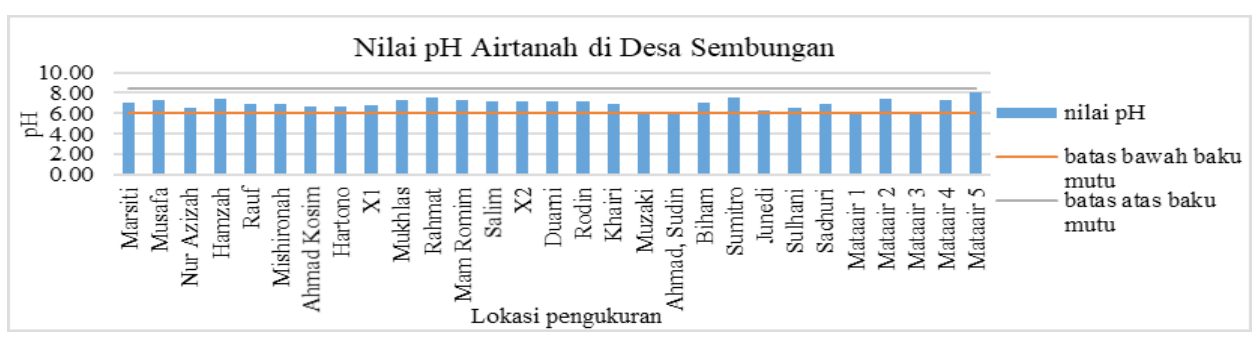

Gambar 9. Grafik nilai pH airtanah Desa Sembungan

Nilai TDS di Desa Sembungan keseluruhan masih berada di bawah baku mutu sesuai dengan Peraturan Menteri Kesehatan No 416 tentang Baku Mutu Air Bersih Tahun 1990, yakni <1.500 ppm dan dan termasuk ke dalam kategori fresh water 0-1000 ppm (Freeze dan Cheery, 1979) (Gambar 8). Semakin besar nilai TDS di wilayah ini maka semakin besar ion terlarutnya sehingga mengindikasikan adanya interaksi yang lebih intesif dan waktu kontak yang lebih lama antara airtanah dengan akuifer. Airtanah yang memiliki nilai TDS tersebar pada titik-titik yang sama dengan airtanah yang memiliki nilai DHL tinggi. Hal tersebut menunjukkan bahwa padatan terlarut yang tinggi dalam airtanah menyebabkan jumlah ion-ion terlarut per volume dan mobilitas ion-ion meningkat.

Nilai pH secara tidak langsung berkaitan dengan DHL dan TDS. Besarnya nilai $\mathrm{pH}$ di Desa Sembungan pada seluruh lokasi pengukuran masih berada dalam kisaran baku mutu, yakni 6,5-8,5 sehingga memenuhi syarat untuk air minum (Gambar 9). Kondisi pH yang mendekati netral ini terindikasi dipengaruhi oleh kondisi geologi wilayah karena ditemukan batuan dengan material penyusun berupa diorite yang bersifat intermediet dari galian sumur milik warga Desa Sembungan. Tinggi rendahnya nilai $\mathrm{pH}$ pada dasarnya tidak berpengaruh pada kesehatan manusia, namun $\mathrm{pH}$ yang nilainya lebih rendah dari 6,5 dapat menyebabkan korosi pada metal sehingga dapat melarutkan unsurunsur seperti timbal dan tembaga yang sifatnya racun (Sudadi, 2003).

\section{KESIMPULAN}

Pola sistem aliran airtanah Desa Sembungan mengalir dari daerah utara yang merupakan daerah imbuhan menuju ke arah barat daya yang merupakan daerah lepasan dengan mataair. Nilai konduktivitas hidrolik daerah kajian sebesar $0.0196 \mathrm{~m} /$ hari, sehingga dihasilkan potensi dinamis airtanah Desa Sembungan sebesar 726,24 liter/hari. Berdasarkan nilai K tersebut maka material penyusun akuifer teridentifikasi sebagai basalt. Mataair di wilayah kajian menjadi pembatas sistem airtanah sekaligus sebagai sumberdaya airtanah Desa Sembungan yang dimanfaatkan oleh masyarakat sebagai kebutuhan domestik, pertanian dan patiwisata. Rata-rata debit mataair di Desa Sembungan adalah 1,15 liter/detik. Kualitas air di sumur gali permukiman dan mataair, baik dari parameter suhu, DHL, TDS, maupun
pH masih tergolong aman untuk konsumsi masyarakat Desa Sembungan karena berada di bawah baku mutu.

\section{UCAPAN TERIMA KASIH}

Terima kasih kepada Kepala Desa Sembungan dan seluruh Pemerintah Wonosobo yang telah bekerja sama dalam pelaksanaan Kuliah Kerja Lapangan (KKL) 3. Terima kasih kepada seluruh masyarakat Desa Sembungan yang telah membantu dalam proses pengambilan data penelitian. Terima kasih kepada Lilik Ismangil sebagai tim teknisi dari Laboratorium Hidrologi dan Klimatologi Lingkungan Fakultas Geografi UGM yang telah memandu dalam melakukan pumping test. Terima kasih kepada seluruh tim KKL 3 serta dosen pembimbing KKL 3 Departemen Geografi Lingkungan Fakultas Geografi Tahun 2017 yang telah memberi arahan dan izin sehingga penelitian ini dapat berlangsung.

\section{DAFTAR PUSTAKA}

Asdak, C., (1995), Hidrologi dan Pengelolaan Daerah Aliran Sungai, Gadjah Mada University Press, Yogayakarta.

Asrifah, D., (2012), Evaluasi Potensi airtanah Bebas untuk Penyediaan Air di Kalasan dan Prambanan, Majalah Geografi Indonesia, 27 (1), 56-78.

Freeze dan Cherry, (1979), Groundwater Hydrology, Prentice-Hall, New Jersey.

Hardjito, (2014), Metode Pumping Test Sebagai Kontrol Untuk Pengambilan Airtanah Secara Berlebihan. Jurnal Sains dan Teknologi Lingkungan, 6, 138149.

Heath, R. C., (1983), Basic Ground-Water Hydrology, US Geological Survey Water, Reston.

Hendrayana, H. dan Vicente, V. A. D. S., (2013), Cadangan Airtanah Berdasarkan Geometri dan Konfigurasi Sistem Akuifer Cekungan Airtanah Yogyakarta-Sleman, Prosiding Seminar Nasional Kebumian Ke-6 Teknik Geologi Universitas Gadjah Mada, 356-370.

Kodoatie, R. J. dan Roestam, S., (2010), Tata Ruang Air, Andi, Yogyakarta.

Kuliah Kerja Lapangan III Geografi Lingkungan. 2017. Laporan Kuliah Kerja Lapangan III: Analisis Sumberdaya Lingkungan dan Wilayah Desa Sembungan, Kecamatan Kejajar, Kabupaten Wonosobo. Yogyakarta: Departemen Geografi Lingkungan Fakultas Geografi UGM 
Linsley, R. K. dan Franzini, J. B. (1985), Teknik Sumberdaya Air Jilid 1 Edisi Ketiga, diterjemahkan oleh Sasongko, D., Erlangga, Jakarta.

Peraturan Menteri Kesehatan Nomor 416/MENKES/ PER/IX/1990 tentangSyarat-syarat dan Pengawasan Kualitas Air.

Peraturan Pemerintah Nomor 82 Tahun 2001 tentang Pengelolaan Kualitas Air dan Pengendalian Pencemaran Air.

Purnama, S. (2010), Hidrologi Air Tanah, Kanisius, Yogyakarta.

Riyadi, A., Kusno, W., Mardi, W., dan Sabaruddin, W.T., (2005), Identifikasi Potensi Air Tanah di Kecamatan Mangkubimi Tasikmalaya dengan Metode Uji Pompa. Jurnal Teknik Lingkungan P3PL - BPPT, 6 (2), 365-371.

Santosa, L.W. dan Adji, T. N., (2014), Karakteristik Akuifer dan Potensi Airtanah Graben Bantul, Gadjah Mada University Press, Yogyakarta.

Setianto, H., Tjahyo N. A., dan Andri K., (2016), Analisis Kualitas Dan Pengelolaan Mata Air di Sekitar Pembangkit Listrik Tenaga Panas Bumi (PLTP) Desa Sikunang Kecamatan Kejajar Kabupaten Wonosobo. Majalah Geografi Indonesia, 30 (1), 2936.

Simoun, S., (2000), Monitoring The Seawater Intrusion Into Coastal-Aquifer Using Geo-Electrical Sounding, A Case Study Of The Northern-Coastal Area of Central Java Indonesia. The Indonesian Journal of Geography, 32 (78-90), 13-47.

Sudadi, P., (2003), Penentuan Kualitas Airtanah melalui Analisis Unsur Kimia Terpilih, Buletin Geologi Tata Lingkungan, 13 (2), 81-89.

Sudarmadji, Hadi, P., dan Widyastuti, M., (2016), Pengelolaan Sumberdaya Air Terpadu, Gadjah Mada University Press, Yogyakarta.

Sunarwan, B., Kamal, N., dan Luthfi, M., (2015), Identifikasi Parameter Fisika dan Kimia Airtanah pada Akifer Endapan Produk Gunung Api, Jurnal Teknologi, 2 (26), 53-58.

Todd, D.K., (1980), Groundwater Hydrology Second Edition, John Wiley and Sons, New York. 